\title{
Survey of insect pests of stored grain in New Zealand
}

\author{
R.B. Chapman ${ }^{1}$, J.W.M. Marris ${ }^{2}$ and J.B. Drummond ${ }^{3}$ \\ ${ }^{1}$ Insect Science Solutions, 830 Selwyn Road, RD 8, Christchurch, 7678, New Zealand \\ ${ }^{2}$ Bio-Protection Research Centre, PO Box 85084, Lincoln University, 7647, New Zealand \\ ${ }^{3}$ Foundation for Arable Research, PO Box 23133, Templeton, 8445, New Zealand \\ Corresponding author: jo.drummond@far.org.nz
}

\begin{abstract}
Producers and processors of cereal grains in New Zealand were invited in August 2015 to submit grain samples to allow extraction and identification of any insect pest species present. Sixty grain samples were received, of which $73 \%$ were infested with one or more insect species. These were predominantly Coleoptera and Psocoptera. The most frequently encountered beetle species were Oryzaephilus surinamensis, Cryptolestes ferrugineus and Cortinicara hirtalis. The Psocoptera were predominantly unidentified species of Liposcelis. Sitophilus species and lepidopteran pests were notable by their absence. The proportion of storage facilities infested by insects in this survey (73\%) was higher than two previous surveys (38\%, 50-63\%), and the proportion of storage facilities treated with insecticides (62\%) was lower than a previous survey $(83 \%)$.
\end{abstract}

Keywords Stored product insects, survey, cereal grain, Oryzaephilus surinamensis, Cryptolestes ferrugineus, Cortinicara hirtalis, Liposcelis sp.

\section{INTRODUCTION}

Cereal grain crops form a significant part of arable production in New Zealand. In 2015, 425,000 t of wheat were produced from 48,600 ha, 452,400 $\mathrm{t}$ of barley from 67,200 ha, 33,600 t of oats from 6,400 ha and 224,300 t of maize grain from 19,500 ha (Statistics New Zealand 2015). Much of this grain is stored in on-farm facilities and some larger grain storage consolidation sites, until it is required for processing or other uses. Stored grain pests remain a persistent problem for cereal producers in New Zealand, however, there has been no new information published on grain storage issues since 1999 (Hill 1999). Furthermore, specific information on the species of arthropod pests found in stored grain and their incidence is fragmentary as very few surveys of grain storage facilities have been carried out in the past. The most recent surveys occurred in the 1970-80s (French 1971; Ferguson 1979; K.G. Somerfield, Palmerston North, personal communication). Consequently, there is no current information on species prevalence, their distribution, incidence or economic impact.

There is a need to review the status of stored grain pests to guide the development of sustainable pest management programmes. This situation is made more urgent by the fact that New Zealand primarily remains reliant on a single organophosphate insecticide, pirimiphos-methyl, to control stored grain pests. With organophosphates being subject to review in New Zealand and elsewhere, it is possible their use in grain treatment will not be acceptable in the future. There are also anecdotal reports this insecticide is now less effective against 
stored grain pests than in the past, but the reason for this has not been established. The objective of this qualitative survey was to identify the key arthropod species currently found in stored grain across the grain producing areas of New Zealand.

\section{MATERIALS AND METHODS}

An invitation was sent to grain growers on the Foundation for Arable Research (FAR) mailing list to participate in a survey on stored grain pests. A plastic bag for grain samples (ca $500 \mathrm{~g}$ ) was sent with instructions to those growers wishing to participate. Growers were asked to sample grain from areas of known infestation. A similar invitation was sent to selected feed manufacturers and millers. A brief questionnaire was included with each sample bag asking whether insecticide treatment(s) had been made in the storage facility in the past 12 months and what product(s) had been used. The locality from which samples were collected was also requested. Sixty grain samples were submitted from throughout New Zealand during late August and early September, 2015.

Grain samples were sieved through a nest of sieves to separate any insects and mites from the grain. Collected insects and the fine siftings were transferred to $70 \%$ alcohol for storage until insect identification was carried out. Representative specimens were mounted as appropriate and identifications were made using relevant taxonomic keys. Confirmatory identifications were obtained from specialists for certain insect groups. Mounted and alcohol-preserved reference specimens were deposited in the Entomology Research Collection, Lincoln University.

\section{RESULTS}

Grain samples (number in parentheses) were received from Marlborough (1), Canterbury (39), Otago (3) and Southland (7) in the South Island, and Gisborne (1), Hawke's Bay (4), Manawatu (3) and Wairarapa (2) in the North Island. The majority of samples were barley (30) and wheat (24), with a smaller number of maize (3), oats (1), ryecorn (1) and linseed (1) samples. Overall, $73.3 \%$ of grain samples were infested by one or more insect species. By crop, the percentage of samples infested were as follows (percentage in parentheses): barley (76.7\%), wheat (75\%), maize $(66.7 \%)$, oats (100\%), ryecorn (0\%), linseed (0\%).

Of the 60 respondents, 37 indicated the grain

Table 1 Insects extracted from stored grain samples from throughout New Zealand, August 2015.

\begin{tabular}{|c|c|c|c|}
\hline Species/taxonomic group & Common name & $\begin{array}{l}\text { Samples } \\
\text { infested }\end{array}$ & $\begin{array}{l}\text { Percentage infested } \\
\qquad(\mathrm{n}=60)\end{array}$ \\
\hline Oryzaephilus surinamensis (L.) & Sawtoothed grain beetle & 12 & 20.0 \\
\hline Cryptolestes ferrugineus Stephens & Flat grain beetle & 7 & 11.7 \\
\hline Latridiidae species $^{1}$ & Minute mould beetles & 7 & 11.7 \\
\hline Ahasverus advena (Waltl) & Foreign grain beetle & 2 & 3.3 \\
\hline Rhizopertha dominicana (F.) & Lesser grain borer & 1 & 1.7 \\
\hline Typhaea stercorea (L.) & Hairy fungus beetle & 1 & 1.7 \\
\hline Pscoptera species $^{2}$ & Psocids, booklice & 30 & 50.0 \\
\hline Thysanoptera species & Thrips & 9 & 15.0 \\
\hline Undetermined beetle species & & 9 & 15.0 \\
\hline Unidentified insect parts & & 5 & 8.3 \\
\hline
\end{tabular}


or grain storage facilities had been treated one or more times with insecticides in the previous 12 months. The majority of grain or storage facilities (32) were treated with various formulations (dust, smoke, liquid) of pirimiphos-methyl, while the others were treated with dichlorvos (1), maldison (1), permethrin (1) or the fumigant magnesium phosphide (2). By crop, the number treated with one or more applications of insecticides or fumigants were: barley (19), wheat (16), maize (1), oats (1), ryecorn (0) and linseed (0).

Of the 60 grain samples submitted, 16 had no insect species extracted from them, 20 samples had just one species present, 16 samples had two species present and eight samples had three or more species present. Of the grain samples or storage structures that had been treated with insecticides, eight of the 16 with no insect species present had been treated, 11 of the 20 with one species present had been treated, 12 of the 16 with two species present had been treated and six of the eight with three or more species present had been treated with insecticide.

A range of insect species was extracted from the stored grain samples (Table 1). Sawtoothed grain beetle, flat grain beetle and minute mould beetles (two species) were the most frequently extracted Coleoptera, while psocids were extracted from $50 \%$ of all grain samples. Thrips species were likely a by-catch from harvest and are not regarded to be stored product pests. Beetle species were mostly extracted from barley and wheat samples (29) grown predominantly in the Canterbury region. Psocids were also predominantly extracted from wheat and barley samples (22) from the Canterbury region, although they were also extracted from barley, wheat and maize samples (7) from all North Island regions.

\section{DISCUSSION}

This survey was conducted to provide a 'snap-shot' of insect pest species currently found in stored cereal grains in New Zealand for comparison with those found in previous surveys, and as a precursor to a more formal survey proposed for 2016. French (1971) carried out the first systematic survey of farm-stored bulk wheat in Canterbury over five years (1967-1971) and found, overall, $62 \%$ of grain storage facilities had no infestations of stored grain pests, $24 \%$ had a trace to light infestations and $14 \%$ had medium to heavy infestations of one or more pest species. This contrasts with $73 \%$ of grain samples in the current survey being infested by one or more species, and is also higher than the survey carried out by Ferguson (1979) who, from a postal survey of respondents' perceptions of infestations of stored product pests, reported $50 \%$ to $63 \%$ of stored wheat and barley, respectively, were infested by insects. These are the only comparable studies, although K. Somerfield (K.G. Somerfield, Palmerston North, personal communication) conducted a survey of commercial storage facilities throughout the eastern South Island of New Zealand from 1972-75 but no infestation data were published. One further study, which included on-farm grain storage facilities was focused on Lepidoptera (Cox 1986). However, no Lepidoptera species were extracted from samples in the current survey and therefore they are not considered further.

As noted by French (1971), the occurrence of stored grain pests can vary from year to year both in terms of species presence and abundance. Variation in infestation levels between the current and previous surveys may also be due to different sampling and insect extraction techniques used in the respective studies. As grain samples were requested from participants in the current survey, it is possible that this has biased the samples towards those known to have infestations of insects, which could account for the relatively high percentage of infested samples in some grain samples. There were no apparent trends in the proportion of grain samples infested between grain type, locality and whether or not insecticides had been applied. However, there was a higher proportion $(83 \%)$ of barley and wheat infested with insects from the Canterbury region compared with other localities.

The insects extracted from grain samples were dominated by species of Coleoptera and Psocoptera (Table 1). Of the Coleoptera, Oryzaephilus surinamensis was the most frequently 
found species. This species is a secondary pest of stored products worldwide (Rees 2004), and is established and widespread in New Zealand (Archibald \& Chalmers 1983). It was also recorded in the surveys by French (1971) and Ferguson (1979) and K. Somerfield (K.G. Somerfield, Palmerston North, personal communication). The current survey found this species in samples from the Canterbury and Manawatu regions.

Cryptolestes ferrugineus was also commonly extracted in our grain samples, and a Cryptolestes species was also recorded by French (1971). This species is a widespread secondary pest of a range of stored products including grain (Rees 2004). Archibald \& Chalmers (1983) recorded it as being established in New Zealand and distributed in Hastings, Masterton and mid-Canterbury. The current survey only found this species in samples from the Canterbury region.

Minute mould beetles (Latridiidae) were also commonly found in grain samples from the Canterbury region. Cortinicara hirtalis was the most common species, but it was not recorded in the surveys by French (1971), Ferguson (1979) or K. Somerfield (K.G. Somerfield, Palmerston North, personal communication). This species, formerly known as Corticaria hirtalis Broun, is known from New Zealand and Australia but has not been recorded previously from stored grain in New Zealand or considered a grain pest.

Other less commonly found beetle species were Ahasverus advena, Rhizopertha dominicana and Typhaea stercorea. None of these species was recorded by Ferguson (1979) and K. Somerfield (K.G. Somerfield, Palmerston North, personal communication) in their surveys, and only $A$. advena was recorded by French (1971). Both $A$. advena and $T$. stercorea are recorded as being widespread and established in New Zealand, whereas R. dominicana is recorded as being 'probably established', being found between Auckland and Dunedin (Archibald \& Chalmers 1983).

Notable beetle species omissions from the current survey, but which have been recorded in previous surveys, were Sitophilus granarius (L.) (French 1971, Ferguson 1979, K.G. Somerfield, Palmerston North, personal communication);
Ptinus tectus Boieldieu (French 1971, K. Somerfield pers. comm.); Trigonogenius globulus Solier, Tribolium castaneum (Herbst), Sitophilus oryzae (L.), Ptinus fur (L.), Alphitobius laevigatus (F.) and Gnatocerus cornutus (F.) ( K.G. Somerfield, Palmerston North, personal communication). Whether these species were present but sample collection methods were not suitable for their collection (e.g., Ptinus and Trigonogenius species are more commonly found in detritus and spillage) or they were genuinely absent from storage facilities cannot be determined at present. However, it is surprising that Sitophilus species were not collected in any samples as they were reputedly abundant in surveys by Ferguson (1979) and K. Somerfield (K.G. Somerfield, Palmerston North, personal communication) and, moreover, they are reported to occur widely in stored grain (Rees 2004).

The most commonly encountered insects in the stored grain samples (50\% of samples) were Pscoptera (Table 1), with most specimens identified as species from the genus Liposcelis. As noted, most specimens were damaged in the extraction process, so further collection and less damaging extraction methods will be required to confirm species identity. Liposcelis sp. was recorded in the survey by French (1971) but not in the surveys by Ferguson (1979) or K. Somerfield K.G. Somerfield, Palmerston North, personal communication), although Somerfield (1981) notes a range of psocids are found in stored grain including Liposcelis species. Rees (2004) states Liposcelis species are found throughout Australia and Oceania and are commonly found in stored products worldwide. They are regarded as secondary pests and mould feeders.

In relation to the information collected on insecticide usage, the survey respondents confirmed that they primarily rely on pirimiphosmethyl to control grain storage pests. Although there was a weak trend suggesting that when there was more than one pest species present a greater proportion of stored grain was treated with insecticide, it is not possible to comment on the correlation between insecticide treatments and presence or absence of pest species from these survey results as no previous history of the pest 
species present was available, or the possible presence of insecticide resistance. What can be concluded is that a significant proportion (62\% overall) treated their grain and/or storage facilities with insecticides, although this is lower than the proportion (83\%) reported earlier by Ferguson (1979). The development of insecticide resistance by stored product pests has been widely documented throughout the world (e.g., Boyer et al. 2012, Arthropod Pesticide Resistance Database) and the majority of beetle species identified in this survey have developed resistance to one or more insecticides from different mode of action classes, including commonly used fumigants (Boyer et al. 2012). Resistance to pirimiphos methyl has been recorded for two species found in this survey, O. surinamensis and T. stercorea (Arthropod Pesticide Resistance Database), but not in the other species found. Resistance to pirimiphos methyl has been reported for Sitophilus oryzae, which was not found in this survey (Boyer et al. 2012). No assessment of the status of resistance to pirimiphos methyl has been carried out for stored product pests in New Zealand, and no insecticide resistance management strategies have been developed for these pests in New Zealand.

This survey of stored grain insects in New Zealand has provided a 'snap shot' of species present on one sampling occasion. Because of the methods used for sample collection and extraction, it is not possible to confirm that the results are representative of New Zealand as a whole. However, it has been valuable to provide guidance and a base for a proposed quantitative survey in 2016. There is a significant need to update our understanding of the status of stored product insects in New Zealand to develop sustainable pest management programmes.

\section{ACKNOWLEDGEMENTS}

We would like to acknowledge Orion AgriScience Ltd for funding this project and the Foundation for Arable Research in-kind support. Dr Mike Thomas, Florida State Collection of Arthropods, USA (Cryptolestes) and Dr Rowan Emberson, Entomology Research Collection, Lincoln
University (Latiridiidae) provided confirmatory identifications for which we are most grateful. We thank Ken Somerfield for information on a previous survey of stored product insects carried out in the South Island during 1972 to 1975.

\section{REFERENCES}

Archibald RD, Chalmers I 1983. Stored product Coleoptera in New Zealand. New Zealand Entomologist 7:371-397.

Arthropod Pesticide Resistance Database. http:// www.pesticideresistance.org/. (accessed 1 February 2016).

Boyer S, Zhang H, Lempérière G 2012. A review of control methods and resistance mechanisms in stored-product insects. Bulletin of Entomological Research 102: 213229.

Cox PD 1986. A survey of stored product Lepidoptera in New Zealand. New Zealand Journal of Experimental Agriculture 14: 7176.

Ferguson AJ 1979. The control of stored product pests in the South Island of New Zealand: a two-part study. Master of Agricultural Science thesis. University of Canterbury (Lincoln College), Christchurch, New Zealand.

French RA 1971. A survey of farm-stored bulk wheat in Canterbury. Proceedings of the $24^{\text {th }}$ New Zealand Weed and Pest Control Conference: 179-182.

Hill M (Editor) 1999. The drying and storage of grain and herbage seeds. Foundation for Arable research, Christchurch, New Zealand. $210 \mathrm{p}$.

Rees D 2004. Insects of stored products. CSIRO Publishing, Collingwood, Australia. 485 p.

Somerfield KG 1981. Insects and mites in commercial grain and seed stores identification. AgLink FPP 369. Ministry of Agriculture and Fisheries, New Zealand. 4 p.

Statistics New Zealand. http://www.stats. govt.nz/browse_for_stats/industry_ sectors/agriculture-horticulture-forestry/ AgriculturalProduction HOTPJun15prov. aspx (accessed 15 March 2016). 